KANSAS JOURNAL of MEDICINE

\section{Initial Diagnosis and Management for Acute Charcot Neuroarthropathy}

Matthew L. Vopat, M.D. ${ }^{1}$, Michelle J. Nentwig, M.D. ${ }^{1}$, Alexander C.M. Chong, MSAE, MSME ${ }^{1,2}$,

Jamie L. Agan, PA-C ${ }^{3}$, Naomi N. Shields, M.D. ${ }^{1,3}$,

Shang-You Yang, M.D., Ph.D.

${ }^{1}$ University of Kansas School of Medicine-Wichita,

Department of Orthopaedics

${ }^{2}$ Via Christi Health, Wichita, KS

${ }^{3}$ Advanced Orthopaedics Associates, Wichita, KS

\section{INTRODUCTION}

Charcot neuroarthropathy, also known as Charcot foot, is a complication of diabetes mellitus where there is progressive degeneration of the joints, but it potentially is devastating in its consequences. ${ }^{1}$ It commonly affects the middle of the foot, hind-foot joints, the ankle, and forefoot joints, and it is believed to result from inflammation in the foot that becomes abnormally protracted due to the underlying neuropathy. ${ }^{2-8}$ The prevalence of Charcot neuroarthropathy is up to $13 \%$ in individuals with diabetes. ${ }^{9-11}$ Patients with Charcot neuroarthropathy encounter increased morbidity and decreased quality of life and mortality. ${ }^{2,4,5,12,13}$ If there is a delay in treatment, Charcot neuroarthropathy could result in ulceration and infection which can lead to amputation of the limb. ${ }^{12-16}$ These patients have a significant financial impact on the health care system through primary care, community care, outpatient costs, increased bed occupancy, and prolonged stays in hospital.

Charcot neuroarthropathy poses many clinical challenges in its diagnosis and management. The often asymptomatic nature of the condition is very similar to ankle sprain, cellulitis, venous thrombosis, inflammatory arthritis, or gout in a healthy patient. ${ }^{5,16-22}$ Missed diagnosis is as high as $79 \%$ which ultimately leads to a delay in treatment for an average of 29 weeks. $11,16,17,20,23-25$

Charcot neuroarthropathy is caused by multiple factors, but essentially it is the result of peripheral neuropathy which is a complication associated with many diseases. ${ }^{2,45}$ The underlying peripheral neuropathy can skew the pain perception the patient experiences and can mislead the clinician on their differential diagnosis of an "inflamed foot". A thorough neurological examination of the foot can uncover the underlying inflammatory and osteolytic disease process of Charcot neuroarthropathy., ${ }^{2,4,11,19,26-29}$

Early recognition and intervention is imperative to avoid the rapid progression toward permanent foot deformity, ulceration, and the possibility of limb loss. ${ }^{16,30,31}$ There are multiple review articles about Charcot neuroarthropathy ${ }^{2,11-13,16,23,25,28,32-34}$, but a lack of guidance on foot screen strategies for primary care and emergency room physicians. There is a need for a comprehensive guideline for initial diagnoses and management on foot care to advocate for increased awareness, thereby leading to earlier diagnosis and treatment by a
In the current study, a thorough literature review of Charcot neuroarthropathy was conducted to evaluate efficacious methods of protocol design and potential barriers to implementation. The literature review also encompassed treatment goals for patients with Charcot neuroarthropathy. Based on the literature review, a foot screen strategies protocol for Charcot neuroarthropathy was devised by the authors and reported here. This protocol contains three parts: (1) pathophysiology of acute Charcot neuroarthropathy to highlight the relationship between the clinical findings and the development of the disease, (2) a comprehensive guideline on how to screen and evaluate Charcot neuroarthropathy, and (3) a brief overview on prevention of Charcot neuroarthropathy in patients with diabetes and other forms of peripheral neuropathy.

Pathophysiology. The underlying cause for Charcot neuroarthropathy is due to peripheral neuropathy, which is a loss of function of the nerves in the periphery of the body. ${ }^{2-4}$ The primary episode of inflammation can result from a number of factors, but ultimately leads to an increase in pro-inflammatory cytokines (interleukin-1 $\beta$ and tumor necrosis factor- $\alpha$ ) which leads to receptor activator of the nuclear factor- $\kappa \mathrm{B}$ ligand (RANKL-NFкB) pathway. Osteoclasts are activated leading to bone lysis followed by clearing of debris. In the presence of autonomic neuropathy, there is increased blood flow to the area, which acts to clear away bony material demineralizing the bone, cartilage, and soft tissue in the region. ${ }^{3}$ However, in the presence of diabetic neuropathy, the patient does not have the protective pain perception. Therefore, they continue to walk on the inflamed foot exacerbating the progressive pathway of osteolysis and osteopenia and weakening the pedal skeleton, leading to the high risk for dislocation and/or fracture..$^{5-8,34,35}$

Charcot neuroarthropathy screening guideline. Figure 1 shows the step-by-step process from initial diagnosis of a patient presenting with symptoms of an inflamed foot in a primary care setting to managing the patient with acute Charcot neuroarthropathy. The detailed pathway/algorithm for initial clinical diagnoses and management of acute Charcot neuroarthropathy should be divided into several phases: clinical assessment, peripheral neuropathy evaluation, initial imaging and lab studies, diagnosis, management, and recommendation. Each phase includes the how, the why, and a stepby-step guideline to making an early diagnosis easier and providing appropriate and immediate management for these patients.

Clinical assessment. A high degree of suspicion of Charcot neuroarthropathy is necessary with thorough history and physical examination when a patient presents with an acute erythematous, warm, or edematous foot, with or without any significant history of trauma or surgery, especially for patients with diabetes and peripheral neuropathy with these symptoms. ${ }^{36}$

History. A thorough patient history of a traumatic event or peripheral neuropathy should be assessed. Approximately $50 \%$ of patients with Charcot neuroarthropathy would remember a precipitating, minor traumatic event, and if no traumatic episode was recalled, the time frame for which the patient noticed changes in their foot shape and/or gait should be documented. About $25 \%$ of patients develop similar changes in the contralateral foot. $11,17,18,22,30,34,37-39$ 
Often, the precipitating factor for acute Charcot neuroarthropathy is not a traumatic event, but rather repetitive micro-trauma on an insensate foot. ${ }^{11,17,18,29}$

A chronic history of diabetes longer than 10 years has a strong association with peripheral neuropathy and potential development of Charcot neuropathy. ${ }^{11,12,34,40-44}$ Due to the strong association between elevated hemoglobin Alc (HbAlc) and the development of Charcot neuropathy, the patients' compliance to their diabetic treatment should be assessed and documented. ${ }^{2}$ Some patients also may be unaware of an underlying diagnosis of diabetes at the time of presentation, thereby diabetes screening is essential. Other potential causes of peripheral neuropathy also should be evaluated such as alcohol abuse, syringomyelia, spinal pathology, vitamin B12 deficiency, heavy metal poisoning, leprosy, tertiary syphilis, and idiopathic form. ${ }^{2,3,8,45}$ Other potential risk factors that can lead to the development of Charcot neuroarthropathy include obesity, advanced age, renal failure, iron deficiency, osteoporosis, and rheumatoid arthritis. ${ }^{2,3,8,45}$

\begin{tabular}{|c|c|}
\hline \multicolumn{2}{|c|}{ Clinical Assessment } \\
\hline Physical Examination & History \\
\hline Localized Edema (decreases with elevation?) & $> \pm$ Recall traumatic event \\
\hline Localized Erythema & \pm History or Risk of Peripheral Neuropathy \\
\hline Temperature of Extremity $\left(>2^{\circ} \mathrm{C}\right.$ from contralateral side) & * Diabetes? \\
\hline \pm Ulcer or History of Ulcers or Osteomyelitis & * Alcoholism? \\
\hline + Pulses & * Spinal Cord Pathology or etc... \\
\hline \pm Deformity & \\
\hline \pm Pain & \\
\hline Vital signs (body temp, respiratory rate, blood pressure, se)? & \\
\hline Check the contralateral side & \\
\hline
\end{tabular}

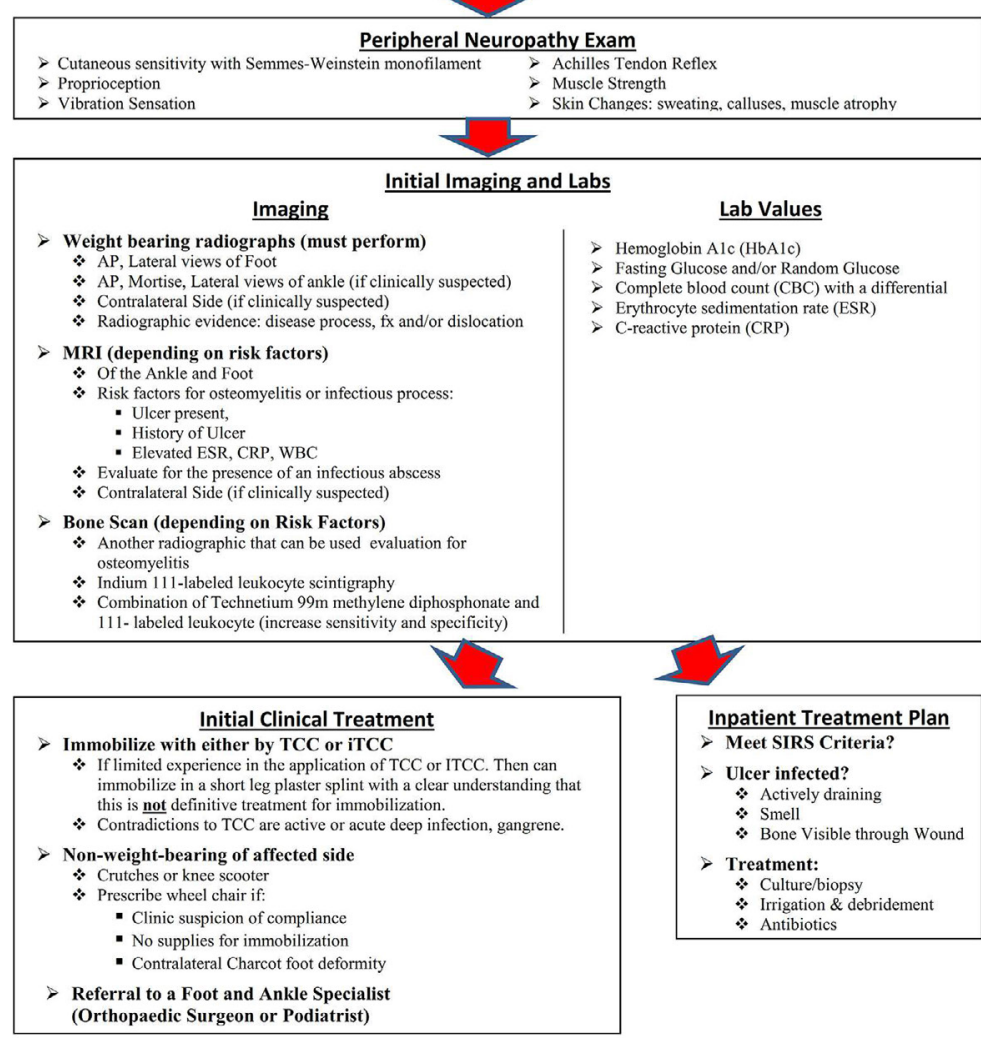

Figure 1. Charcot neuroarthropathy screening and management guideline.
KANSAS JOURNAL of MEDICINE DIAGNOSIS AND MANAGEMENT FOR CHARCOT

NEUROARTHROPATHY

continued.

Physical examination. The classical physical examination findings for an acute Charcot neuroarthropathy are often unilateral localized inflammatory symptoms of the foot, such as edema, erythema, and increased foot temperature of the extremity. ${ }^{2-4,11,21,22,28,34,41}$ A simple physical exam that can be helpful to distinguish between an infectious process and Charcot neuroarthropathy is to have the patient lay supine and elevate the affected extremity for 5 - 10 minutes. Localized edema will decrease with elevation of the extremity in Charcot neuroarthropathy while an infectious process is less likely to decrease. ${ }^{11,46,47}$

The infrared cutaneous temperature monitor to detect foot skin temperature changes is one of the most accurate tools for diagnosis acute Charcot neuroarthropathy. It may be used in the areas of forefoot, mid-foot, and hind-foot. A temperature difference of $2^{\circ} \mathrm{C}$ from the contralateral foot indicates an active Charcot neuroarthropathy. ${ }^{48-50}$

The presence of ulcers or a history of ulcers indicates the need to screen for an active infection. Signs and symptoms, such as purulence, foul smell, or wet gangrene, should be noted., ${ }^{2,51}$ An ulcer with the size over $2 \mathrm{~cm}^{2}$ and visualization of bone increases the risk of developing and/or presence of osteomyelitis. ${ }^{52,53}$

Clinical assessments such as foot tenderness, pedal pulses, and foot deformity should be evaluated. ${ }^{2-4,11,21,22,28,34,41}$ Cutaneous changes such as increased sweating, calluses, and muscle atrophy should be documented. ${ }^{2}$ Owing to the possible presence of peripheral neuropathy, pain may not always be present; with only $50 \%$ of patients reporting pain. ${ }^{28,36,37}$

Charcot neuroarthropathy can present as an infectious process and screening of the patient's vital signs for systemic signs of infection such as fever, chills, elevated heart rate or respiratory rate can be helpful. ${ }^{2,454}$ However, lack of these symptoms may not rule out an infectious process.

Peripheral neuropathy examination. The existence of little or no pain may mislead the patient and physician ${ }^{38}$, as peripheral neuropathy is likely to be an essential prerequisite for the onset of the Charcot neuroarthropathy process. Bilateral neurologic examination should be assessed for numbness, paresthesia, and dysesthesia by evaluating cutaneous sensitivity using Semmes-Weinstein monofilament, proprioception, tuning fork vibration sensation, or Achilles tendon reflex (Figure 2).,4,55-57 The Semmes-Weinstein monofilament test is a noninvasive, low-cost, rapid, and easy-to-apply test that is the most sensitive test in diagnosing peripheral neuropathy. ${ }^{55,56}$ The locations for this test on both feet include the first, third, and fifth metatarsal heads and plantar surface of the distal hallux and third toe, but avoid callused areas. Neuropathy usually starts in the first and third toes and progresses to the first and third metatarsal heads. Seven or less of 10 different touch sensation locations on the patient's foot is an indication of peripheral neuropathy. ${ }^{52,56,58}$ 
KANSAS JOURNAL of MEDICINE

DIAGNOSIS AND MANAGEMENT FOR CHARCOT

NEUROARTHROPATHY

continued.

Imaging. Radiographs are the primary imaging method for initial evaluation of the foot in patients, as they provide information on bone structure, alignment, and mineralization., ${ }^{45,59,60}$ They also are useful in diagnosing the pathology, locating the area of involvement, evaluating quality of bone, and identifying if the process is acute or chronic. It is essential to get plain radiographs on patients present with a symptomatic foot. Unfortunately, radiographic changes of Charcot neuroarthropathy typically are delayed and have low sensitivity. The plain radiographs can be negative for up to three weeks with the only finding being soft tissue swelling. Figure 3 shows an example of the Charcot neuroarthropathy progression on plain radiographs.

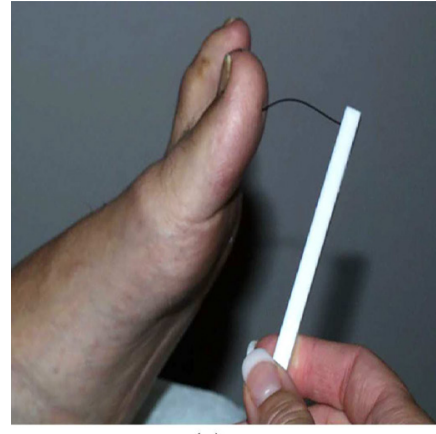

(a)

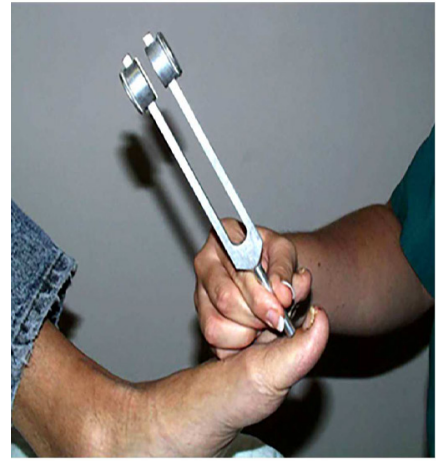

(c)

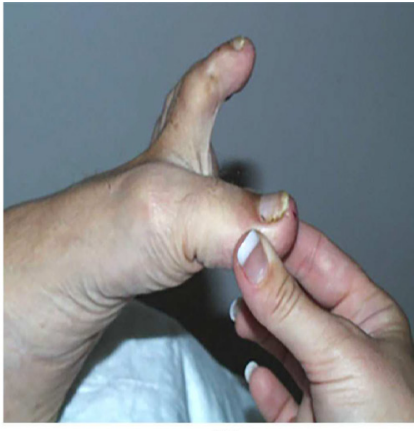

(b)



(d)
Figure 2. Neurologic examinations. (a) Semmes-Weinstein Monofilament test; (b) proprioception test on a big toe; (c) tuning fork vibration sensation test; and (d) Achilles reflex test using a reflex hammer.

The initial radiographic images should include anteroposterior and lateral weight-bearing views of the affected foot and/or full series ankle views (anteroposterior, mortise, and lateral views) depending on clinical suspicion.,60,61 Evidence of demineralization, bone destruction, and periosteal reaction on plain radiographic images can lead towards a diagnosis of Charcot neuroarthropathy, although this also can be seen in chronic osteomyelitis.

If Charcot neuroarthropathy is suspected, magnetic resonance imaging (MRI) allows detection of subtle changes in the early stages when the plain radiographic images appears normal. ${ }^{25} \mathrm{MRI}$ also is useful to rule out osteomyelitis, especially in the presence of an ulcer, history of ulcers, elevated erythrocyte sedimentation rate (ESR), C-reactive protein (CRP), or leukocytosis., ${ }^{2,25,45,62-69}$ The sensitivity and specificity are reported greater than $77 \%$ and $80 \%$ respectively in differentiating acute Charcot neuroathropathy from osteomyelitis. ${ }^{2,45,62-68}$ Osteomyelitis on MRI often displays diffuse marrow involvement that usually only affects a single bone like the metatarsal heads and the calcaneus, ${ }^{4,70}$ whereas Charcot neuroarthropathy more classically exhibits periarticular and subchondral bone marrow edema affecting several joints.,71

Bone scan is another imaging tool that can be used to differentiate osteomyelitis from Charcot neuroarthropathy. A technetium-99m methylene diphosphonate scintigraphy is less useful than leukocyte scintigraphy because there is enrichment on both osteomyelitis and Charcot neuroarthropathy, whereas leukocyte scintigraphy is only positive in osteomyelitis. ${ }^{2,62}$ The combination of technetium-99m methylene diphosphonate scintigraphy with indium-111 white blood cells, labeled leukocyte scintigraphy may improve sensitivity (87\%) and specificity (81\%) for differentiating acute Charcot neuroarthropathy and osteomyelitis., ${ }^{4,59,72-75}$

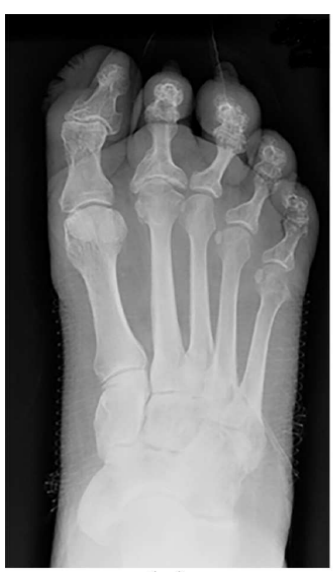

(a)

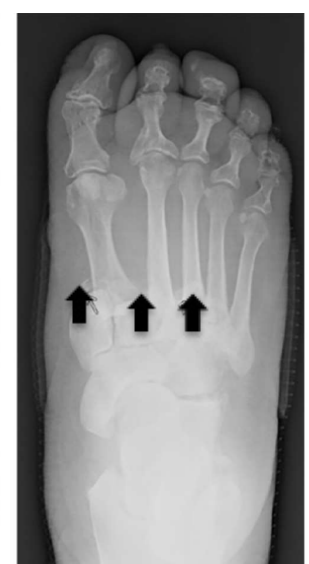

(b)

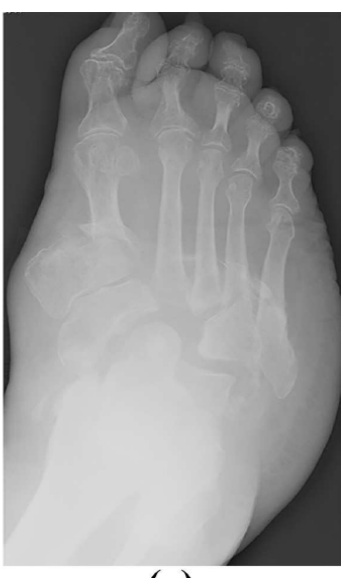

(c)
Figure 3. Progression of a foot Charcot neuroarthropathy on plain radiographs: (a) Initial anteroposterior view of an acute Charcot neuroarthropathy foot; (b) 6-month follow-up, which shows the persistent and progressive joint effusion, narrowing of the joint space, soft tissue calcification, minimal subluxation, osteopenia, and bone fragmentation; and (c) 2-year follow-up, which shows severe destruction of the foot without proper management.

Laboratory tests. There is a strong association between the duration of diabetes, elevated HbAlc, and the development of Charcot neuroarthropathy.,11,76 The patient should be screened initially for uncontrolled diabetes by evaluating fasting glucose, HbAlc, and/or random glucose levels. Even if the patient has no known diabetes history, they should be screened because of the high prevalence of diabetes. ${ }^{25,33,77}$ If these lab values are not elevated and the patient has no known diabetes, then further evaluation should be made for the cause of peripheral neuropathy.

Initial lab orders should include complete blood count (CBC) with a differential, erythrocyte sedimentation rate (ESR), and C-reactive protein (CRP). Elevations in ESR, CRP, and leukocytosis are more in line with an infectious process like osteomyelitis., ${ }^{2,3,34,78}$ An ESR greater than $70 \mathrm{~mm} / \mathrm{h}$ has an 11-fold increased risk for the presence of osteomyelitis. ${ }^{52,79}$ A slight elevation in ESR with normal white blood cell count (WBC) may occur in Charcot neuroarthropathy ${ }^{80}$ Normal inflammatory markers may be noticed occasionally in chronic osteomyelitis; the diagnosis may depend on other modalities like radiographs and MRI.,51 
Treatment. The most important aspect of the success for a foot screen protocol is early management of these suspected Charcot neuroarthropathy patients. Many cases of acute Charcot neuroarthropathy are mistreated because the condition is not recognized widely outside specialist clinics. If the suspected Charcot neuroarthropathy is complicated by ulceration or infection, then an inpatient treatment plan should be implemented before sending the patient home. The gold standard of conservative management strategy for Charcot neuroarthropathy has been immobilization and non-weight bearing. ${ }^{81}$

Inpatient treatment plan. Patients with confirmed or suspected infection, such as cellulitis, deep tissue infection, abscess or osteomyelitis, should be admitted for evaluation, when they have at least two of the following criteria from Systemic Inflammatory Response Syndrome (SIRS): body temperature $\geq 38^{\circ} \mathrm{C}$ or $<36^{\circ} \mathrm{C}$, heart rate $>90$ beats $/$ minute, respiratory rate $>20$ breaths $/ \mathrm{min}$. or arterial carbon dioxide tension (PaCO2) $<32 \mathrm{mmHg}$, abnormal white blood cell count $\geq 12,000 / \mu \mathrm{L}$ or $\leq 4,000 / \mu \mathrm{L}$ or $>10 \%$ immature (bands) forms. ${ }^{82-84}$ Infection in the Charcot neuroarthropathy patient poses great challenges. Discussion with a foot and ankle specialist is recommended about treatment plans such as irrigation and debridement, culture/biopsy of the wound, and antibiotic treatment. Immobilization of the affected foot continues until complete resolution of the acute phase. Patient education regarding the diagnosis, estimated length of treatment, and expected outcomes is an important component of Charcot neuroarthropathy management. If the patient understands the nature of this limb-threatening condition, they may be more motivated to adhere to the management plan. Emphasis on the importance of strict immobilization and attending regular followup reviews may improve the outcome of Charcot neuroarthropathy.

Initial clinical treatment. The initial clinical treatment for a patient suspected of Charcot neuroarthropathy should be immobilization and non-weight bearing of affected foot., ${ }^{2,411,15,81,85-87}$ The goals are to stop the inflammation-mediated damage, relieve pain, and maintain or protect the skeleton of the foot and ankle from further deformity on the affected limb until definitive diagnosis can be made. The use of a total contact cast (TCC; Figure 4), instant total contact cast (iTCC) with the use of crutches, or a knee scooter is recommended. If the clinician has limited experience in the application of TCC or iTCC, they can immobilize the patient in a short leg splint with a clear understanding that this is not the definitive treatment for immobilization. A wheelchair should be prescribed in cases where there is clinical suspicion of non-compliance or a question of bilateral involvement. These treatments are not definitive and the patient should be referred to a foot and ankle specialist (orthopedic or podiatrist) to establish a multidisciplinary team approach for definitive treatment.
KANSAS JOURNAL of MEDICINE

DIAGNOSIS AND MANAGEMENT FOR CHARCOT

NEUROARTHROPATHY

continued.

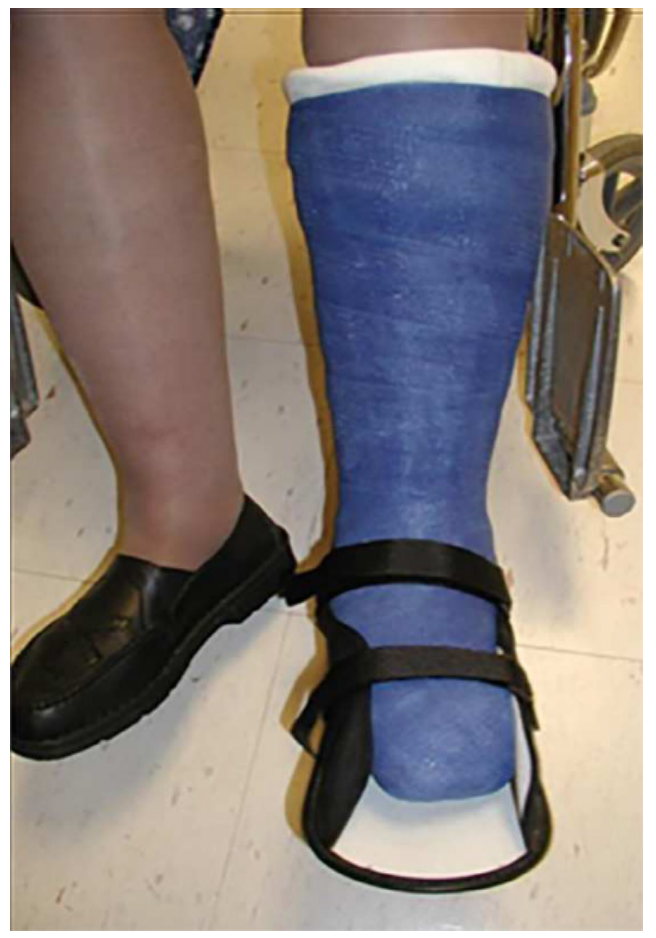

Figure 4. Total contact cast (TCC).

Preventive medicine. Patients with diabetes mellitus and mildto-severe peripheral neuropathy have high potential of developing Charcot neuroarthropathy. It affects 415 million people globally. This number is predicted to rise to 642 million by $2040 .{ }^{88}$ These patients have a significant impact on health care costs, so prevention is important. ${ }^{11,25,76,89}$ Like most complications of diabetes, the key is to control patients' glucose and HbAlc levels either by diet and/or medication. ${ }^{90}$ The American Diabetes Association 2016 guidelines $^{90}$ recommended a glycemic target of $\mathrm{HbAlc}<7.0 \%(53 \mathrm{mmol} / \mathrm{mol})$, preprandial capillary plasma glucose of $80-130 \mathrm{mg} / \mathrm{dL}(4.4-7.2$ $\mathrm{mmol} / \mathrm{L}$ ), and peak postprandial capillary plasma glucose $<180 \mathrm{mg} /$ dL (10 mmol/L) for non-pregnant adults.

Patient education is an essential component of the long-term management, focusing on the importance of appropriate footwear, offloading, regular follow up reviews, and the risk of further complications. ${ }^{27,28}$ Lifestyle changes for obesity, nutrition, smoking and alcohol abuse should be addressed..$^{2}$ A thorough diabetic foot exam to check for any skin abnormalities and a neurological exam should be performed at least two times a year, if the patient shows signs of peripheral neuropathy. It is recommended that the patient be prescribed a hard shoe, diabetic foot wear, or foot orthoses, and advised against wearing sandals to prevent development of Charcot neuroarthropathy. Footwear is an important component of the long-term management of the insensate chronic Charcot neuroarthropathy, ensuring that it remains accommodated and protected. Patients should be educated on regular self-examinations of their feet for skin break down, swelling, erythema and ulcers, and encouraged to evaluate their shoes for any foreign bodies before putting them on. 
KANSAS JOURNAL of MEDICINE

DIAGNOSIS AND MANAGEMENT FOR CHARCOT

NEUROARTHROPATHY

continued.

\section{CONCLUSION}

A thorough neurological examination must be a part of the physical exam for any patient presenting with unilateral erythema, edema, and increased foot temperature that has high risk factors for peripheral neuropathy. This examination could prevent any hidden inflammatory process, like Charcot neuroarthropathy, from going undiagnosed. A protocol for primary care and emergency room physicians provides a comprehensive guideline on foot screening, especially for acute Charcot neuroarthropathy.

\section{ACKNOWLEDGEMENTS}

The authors thank Lisa N. MacFadden, Ph.D., for her assistance with this manuscript.

\section{REFERENCES}

${ }^{1}$ Herbst SA, Jones KB, Saltzman CL. Pattern of diabetic neuropathic arthropathy associated with the peripheral bone mineral density. J Bone Joint Surg Br 2004; 86(3):378-383. PMID: 15125125.

2 Trieb K. The Charcot foot: Pathophysiology, diagnosis and classification. Bone Joint J 2016; 98-B(9):1155-1159. PMID: 27587513.

${ }^{3}$ Papanas N, Maltezos E. Etiology, pathophysiology and classifications of the diabetic Charcot foot. Diabet Foot Ankle 2013; 4. PMID: 23705058.

${ }^{4}$ Gouveri E, Papanas N. Charcot osteoarthropathy in diabetes: A brief review with an emphasis on clinical practice. World J Diabetes 2011;2(5):5965. PMID: 21691556.

5 Jeffcoate WJ. Charcot foot syndrome. Diabet Med 2015; 32(6):760-770. PMID: 25818542.

${ }^{6}$ Baumhauer JF, O'Keefe RJ, Schon LC, Pinzur MS. Cytokine-induced osteoclastic bone resorption in charcot arthropathy: An immunohistochemical study. Foot Ankle Int 2006; 27(10):797-800. PMID: 17054880.

7 Uccioli L, Sinistro A, Almerighi C, et al. Proinflammatory modulation of the surface and cytokine phenotype of monocytes in patients with acute Charcot foot. Diabetes Care 2010; 33(2):350-355. PMID: 19880584.

${ }^{8}$ Kaynak G, Birsel O, Güven MF, Oğüt T. An overview of the Charcot foot pathophysiology. Diabet Foot Ankle 2013; 4. PMID: 23919113.

9 Younis BB, Shahid A, Arshad R, Khurshid S, Masood J. Charcot osteoarthropathy in type 2 diabetes persons presenting to specialist diabetes clinic at a tertiary care hospital. BMC Endocr Disord 2015; 15:28.

PMID: 26065885.

10 Jeffcoate W, Lima J, Nobrega L. The Charcot foot. Diabet Med 2000; 17(4):253-258. PMID: 10821290.

${ }^{11}$ Milne TE, Rogers JR, Kinnear EM, et al. Developing an evidence-based clinical pathway for the assessment, diagnosis and management of acute Charcot neuro-arthropathy: A systematic review. J Foot Ankle Res 2013; 6(1):30. PMID: 23898912.

${ }^{12}$ Pakarinen TK, Laine HJ, Mäenpää H, Mattila P, Lahtela J. Long-term outcome and quality of life in patients with Charcot foot. Foot Ankle Surg 2009; 15(4):187-191. PMID: 19840750.

${ }^{13}$ Chantelau EA, Richter A. The acute diabetic Charcot foot managed on the basis of magnetic resonance imaging--A review of 71 cases. Swiss Med Wkly 2013; 143:wl3831. PMID: 23897135.

${ }_{14}$ Dhawan V, Spratt KF, Pinzur MS, Baumhauer J, Rudicel S, Saltzman CL. Reliability of AOFAS diabetic foot questionnaire in Charcot arthropathy: Stability, internal consistency, and measurable difference. Foot Ankle Int 2005; 26(9):717-731. PMID: 16174503.

${ }^{15}$ Wukich DK, Sung W. Charcot arthropathy of the foot and ankle: Modern concepts and management review. J Diabetes Complications 2009; 23(6):409-426. PMID: 18930414

16 Wukich DK, Sung W, Wipf SA, Armstrong DG. The consequences of complacency: Managing the effects of unrecognized Charcot feet. Diabet Med 2011; 28(2):195-198. PMID: 21219429.

${ }_{17}$ Pakarinen TK, Laine HJ, Honkonen SE, Peltonen J, Oksala H, Lahtela J. Charcot arthropathy of the diabetic foot. Current concepts and review of 36 cases. Scand J Surg 2002; 91(2):195-201. PMID: 12164523.
18 Foltz KD, Fallat LM, Schwartz S. Usefulness of a brief assessment battery for early detection of Charcot foot deformity in patients with diabetes. J Foot Ankle Surg 2004; 43(2):87-92. PMID: 15057854.

${ }^{19}$ Chantelau E. The perils of procrastination: Effects of early vs. delayed detection and treatment of incipient Charcot fracture. Diabet Med 2005; 22(12):1707-1712. PMID: 16401316.

${ }^{20}$ Frykberg RG, Belczyk R. Epidemiology of the Charcot foot. Clin Podiatr Med Surg 2008; 25(1):17-28, v. PMID: 18165108.

${ }^{21}$ Rogers LC, Frykberg RG, Armstrong DG, et al. The Charcot foot in diabetes. Diabetes Care 2011; 34(9):2123-2129. PMID: 21868781.

22 Game FL, Catlow R, Jones GR, et al. Audit of acute Charcot's disease in the UK: the CDUK study. Diabetologia 2012; 55(1):32-35. PMID: 22065087.

${ }_{23}$ Marks RM. Complications of foot and ankle surgery in patients with diabetes. Clin Orthop Relat Res 2001; (391):153-161. PMID: 11603663.

${ }^{24}$ Myerson MS, Henderson MR, Saxby T, Short KW. Management of midfoot diabetic neuroarthropathy. Foot Ankle Int 1994; 15(5):233-241. PMID: 7951961

${ }^{25}$ Stark C, Murray T, Gooday C, et al. 5 year retrospective follow-up of new cases of Charcot neuroarthropathy-A single centre experience. Foot Ankle Surg 2016; 22(3):176-180. PMID: 27502226.

26 Blatchford L, Morey P, McConigley R. Identifying type 2 diabetes risk classification systems and recommendations for review of podiatric care in an Australian Aboriginal health clinic. Journal Foot Ankle Res 2015; 8:34. PMID: 26229555.

${ }^{27}$ Wraight PR, Lawrence SM, Campbell DA, Colman PG. Creation of a multidisciplinary, evidence based, clinical guideline for the assessment, investigation and management of acute diabetes related foot complications. Diabet Med 2005; 22(2):127-136. PMID: 15660728.

${ }_{28}$ Baglioni P, Malik M, Okosieme OE. Acute Charcot foot. BMJ 2012; 344:el397. PMID: 22419788.

29 Foster A. An evaluation of NICE guidelines on foot care for patients with diabetes. Nurs Times 2004; 100(22):52-53. PMID: 15195547.

30 Jeffcoate WJ. Charcot neuro-osteoarthropathy. Diabetes Metab Res Rev 2008; 24(Suppl 1):S62-65. PMID: 18393327.

${ }^{31}$ Eichenholtz SN. Charcot Joints. SpringField, IL: Charles C Thomas, 1966.

${ }^{32}$ La Fontaine J, Lavery L, Jude E. Current concepts of Charcot foot in diabetic patients. Foot (Edinb) 2016; 26:7-14. PMID: 26802944.

33 Schneekloth BJ, Lowery NJ, Wukich DK. Charcot neuroarthropathy in patients with diabetes: An updated systematic review of surgical management. J Foot Ankle Surg 2016; 55(3):586-590. PMID: 26810129.

${ }^{34}$ Varma AK. Charcot neuroarthropathy of the foot and ankle: A review. J Foot Ankle Surg 2013; 52(6):740-749. PMID: 23965177.

35 Wünschel M, Wülker N, Gesicki M. Charcot arthropathy of the first metatarsophalangeal joint. J Am Podiatr Med Assoc 2012; 102(2):161-164. PMID: 22461274 .

${ }^{36}$ Botek G, Anderson MA, Taylor R. Charcot neuroarthropathy: An often overlooked complication of diabetes. Cleve Clin J Med 2010; 77(9):593-599. PMID: 20810870.

37 Petrova NL, Edmonds ME. Charcot neuro-osteoarthropathy-current standards. Diabetes Metab Res Rev 2008; 24(Suppl 1):S58-61.

PMID: 18442182.

${ }^{38}$ Rogers LC, Bevilacqua NJ. The diagnosis of Charcot foot. Clin Podiatr Med Surg 2008; 25(1):43-5l, vi. PMID: 18165110.

${ }^{39}$ Chantelau E, Kimmerle R, Poll LW. Nonoperative treatment of neuroosteoarthropathy of the foot: Do we need new criteria? Clin Podiatr Med Surg 2007; 24(3):483-503, ix. PMID: 17613387.

${ }^{40}$ Leung HB, Ho YC, Wong WC. Charcot foot in a Hong Kong Chinese diabetic population. Hong Kong Med J 2009; 15(3):191-195. PMID: 19494374. ${ }^{41}$ Pakarinen TK, Laine HJ, Mäenpää H, Mattila P, Lahtela J. The effect of zoledronic acid on the clinical resolution of Charcot neuroarthropathy: A pilot randomized controlled trial. Diabetes Care 2011; 34(7):1514-1516. PMID: 21593295.

${ }^{42}$ Moura-Neto A, Fernandes TD, Zantut-Wittmann DE, et al. Charcot foot: Skin temperature as a good clinical parameter for predicting disease outcome. Diabetes Res Clin Pract 2012; 96(2):ell-14. PMID: 22296852.

43 Sämann A, Pofahl S, Lehmann T, et al. Diabetic nephropathy but not $\mathrm{HbAlc}$ is predictive for frequent complications of Charcot feet - long-term follow-up of 164 consecutive patients with 195 acute Charcot feet. Exp Clin Endocrinol Diabetes 2012; 120(6):335-339. PMID: 22421981.

${ }^{44}$ Christensen TM, Bülow J, Simonsen L, Holstein PE, Svendsen OL. Bone mineral density in diabetes mellitus patients with and without a Charcot foot. Clin Physiol Funct Imaging 2010; 30(2):130-134. PMID: 20089075. 
45 Trieb K, Hofstätter SG. [Pathophysiology and etiology of the Charcot foot]. Orthopade 2015; 44(1):2-7. PMID: 25413280.

${ }^{46}$ Ndip A, Jude EB, Whitehouse R, Prescott M, Boulton AJ. Charcot neuroarthropathy triggered by osteomyelitis and/or surgery. Diabet Med 2008; 25(12):1469-1472. PMID: 19046247.

47 Brodsky JW. The Diabetic Foot. In: RA Mann, MJ Coughlin (Eds). Surgery of the Foot and Ankle. St. Louis: Mosby, 1993.

${ }^{48}$ Madan SS, Pai DR. Charcot neuroarthropathy of the foot and ankle. Orthop Surg 2013; 5(2):86-93. PMID: 23658042.

49 Khanolkar MP, Bain SC, Stephens JW. The diabetic foot. QJM 2008; 101(9):685-695. PMID: 18353793.

50 Armstrong DG, Lavery LA, Liswood PJ, Todd WF, Tredwell JA. Infrared dermal thermometry for the high-risk diabetic foot. Phys Ther 1997; 77(2):169-175; discussion 176-177. PMID: 9037217.

${ }^{51}$ Mascarenhas JV, Jude EB. Pathogenesis and medical management of diabetic Charcot neuroarthropathy. Med Clin North Am 2013; 97(5):857872. PMID: 23992897.

${ }_{52}$ Malhotra R, Chan CS, Nather A. Osteomyelitis in the diabetic foot. Diabet Foot Ankle 2014; 5. PMID: 25147627.

${ }_{53}$ Newman LG, Waller J, Palestro CJ, et al. Unsuspected osteomyelitis in diabetic foot ulcers. Diagnosis and monitoring by leukocyte scanning with indium in 111 oxyquinoline. JAMA 1991; 266(9):1246-1251.

PMID: 1908030.

${ }^{54}$ Petrova NL, Moniz C, Elias DA, Buxton-Thomas M, Bates M, Edmonds ME. Is there a systemic inflammatory response in the acute charcot foot? Diabetes Care 2007; 30(4):997-998. PMID: 17392560.

55 Guyton GP, Saltzman CL. The diabetic foot: Basic mechanisms of disease. Instr Course Lect 2002; 51:169-181. PMID: 12064102.

56 Feng Y, Schlösser FJ, Sumpio BE. The Semmes Weinstein monofilament examination as a screening tool for diabetic peripheral neuropathy. J Vasc Surg 2009; 50(3):675-682.el. PMID: 19595541.

${ }_{57}$ Graves M, Tarquinio TA. Diabetic neuroarthropathy (Charcot joints): The importance of recognizing chronic sensory deficits in the treatment of acute foot and ankle fractures in diabetic patients. Orthopedics 2003; 26(4):415-418. PMID: 12722914.

58 Nather A, Wong KL. Distal amputations for the diabetic foot. Diabet Foot Ankle 2013; 4. PMID: 23869251.

59 Trepman E, Nihal A, Pinzur MS. Current topics review: Charcot neuroarthropathy of the foot and ankle. Foot Ankle Int 2005; 26(1):46-63.

PMID: 15680119.

${ }^{60}$ van der Ven A, Chapman CB, Bowker JH. Charcot neuroarthropathy of the foot and ankle. J Am Acad Orthop Surg 2009; 17(9):562-571.

PMID: 19726740.

${ }^{61}$ Gold RH, Tong DJ, Crim JR, Seeger LL. Imaging the diabetic foot. Skeletal Radiol 1995; 24(8):563-571. PMID: 8614854.

62 Sanverdi SE, Ergen BF, Oznur A. Current challenges in imaging of the diabetic foot. Diabet Foot Ankle 2012; 3. PMID: 23050068.

63 Shibata T, Tada K, Hashizume C. The results of arthrodesis of the ankle for leprotic neuroarthropathy. J Bone Joint Surg Am 1990; 72(5):749-756. PMID: 2355038.

${ }^{64}$ Chantelau EA, Grutzner G. Is the Eichenholtz classification still valid for the diabetic Charcot foot? Swiss Med Wkly 2014; 144:wl3948.

PMID: 24764120.

65 Butt DA, Hester T, Bilal A, Edmonds M, Kavarthapu V. The medial column Synthes Midfoot Fusion Bolt is associated with unacceptable rates of failure in corrective fusion for Charcot deformity: Results from a consecutive case series. Bone Joint J 2015; 97-B(6):809-813. PMID: 26033061.

${ }_{66}$ Siebachmeyer M, Boddu K, Bilal A, et al. Outcome of one-stage correction of deformities of the ankle and hindfoot and fusion in Charcot neuroarthropathy using a retrograde intramedullary hindfoot arthrodesis nail. Bone Joint J 2015; 97-B(1):76-82. PMID: 25568417.

67 Dayton P, Feilmeier M, Thompson M, Whitehouse P, Reimer RA. Comparison of complications for internal and external fixation for Charcot reconstruction: A systematic review. J Foot Ankle Surg 2015; 54(6):10721075. PMID: 26215548.

${ }^{68}$ Game FL. Osteomyelitis in the diabetic foot: Diagnosis and management. Med Clin North Am 2013; 97(5):947-956. PMID: 23992902.

${ }^{69}$ McCarthy E, Morrison WB, Zoga AC. MR imaging of the diabetic foot. Magn Reson Imaging Clin North Am 2017; 25(1):183-194. PMID: 27888847. ${ }^{70}$ Ledermann HP, Morrison WB, Schweitzer ME. MR image analysis of pedal osteomyelitis: Distribution, patterns of spread, and frequency of associated ulceration and septic arthritis. Radiology 2002; 223(3):747-755. PMID: 12034944.
KANSAS JOURNAL of MEDICINE

DIAGNOSIS AND MANAGEMENT FOR CHARCOT

\section{NEUROARTHROPATHY}

continued.

${ }^{71}$ Stevens MJ, Edmonds ME, Foster AV, Watkins PJ. Selective neuropathy and preserved vascular responses in the diabetic Charcot foot. Diabetologia 1992; 35(2):148-154. PMID: 1547919,

72 Rajbhandari SM, Jenkins RC, Davies C, Tesfaye S. Charcot neuroarthropathy in diabetes mellitus. Diabetologia 2002; 45(8):1085-1096.

PMID: 12189438.

${ }^{73}$ Palestro CJ, Mehta HH, Patel M, et al. Marrow versus infection in the Charcot joint: Indium-111 leukocyte and technetium-99m sulfur colloid scintigraphy. J Nucl Med 1998; 39(2):346-350. PMID: 9476948.

${ }^{74}$ Crerand S, Dolan M, Laing P, Bird M, Smith ML, Klenerman L. Diagnosis of osteomyelitis in neuropathic foot ulcers. J Bone Joint Surg Br 1996; 78(1):5l-55. PMID: 8898126.

75 Pinzur MS, Lio T, Posner M. Treatment of Eichenholtz stage I Charcot foot arthropathy with a weightbearing total contact cast. Foot Ankle Int 2006; 27(5):324-329. PMID: 16701052.

76 Stuck RM, Sohn MW, Budiman-Mak E, Lee TA, Weiss KB. Charcot arthropathy risk elevation in the obese diabetic population. Am J Med 2008; 121(11):1008-1014. PMID: 18954849.

77 U.S. Centers for Disease Control and Prevention. National Diabetes Statistics Report, 2014. Estimates of diabetes and its burden in the United States. Available at: https://www.cdc.gov/diabetes/pdfs/data/2014-reportestimates-of-diabetes-and-its-burden-in-the-united-states.pdf. Accessed May 15, 2018.

78 Larson SA, Burns PR. The pathogenesis of Charcot neuroarthropathy: Current concepts. Diabet Foot Ankle 2012; 3. PMID: 22396834.

79 Butalia S, Palda VA, Sargeant RJ, Detsky AS, Mourad O. Does this patient with diabetes have osteomyelitis of the lower extremity? JAMA 2008; 299(7):806-813. PMID: 18285592.

80 Sanders L, Mrdjenovich, D. Anatomical patterns of bone and joint destruction in neuropathic diabetics. Diabetes 1991; 40(Supp 1):529A.

${ }^{81}$ Clohisy DR, Thompson RC Jr. Fractures associated with neuropathic arthropathy in adults who have juvenile-onset diabetes. J Bone Joint Surg Am 1988; 70(8):1192-1200. PMID: 3417704.

${ }^{82}$ Comstedt P, Storgaard M, Lassen AT. The Systemic Inflammatory Response Syndrome (SIRS) in acutely hospitalised medical patients: A cohort study. Scand J Trauma Resusc Emerg Med 2009; 17:67.

PMID: 20035633.

${ }^{83}$ Bone RC, Balk RA, Cerra FB, et al. Definitions for sepsis and organ failure and guidelines for the use of innovative therapies in sepsis. The ACCP/ SCCM Consensus Conference Committee. American College of Chest Physicians/Society of Critical Care Medicine. Chest 1992; 101(6):1644-1655. PMID: 1303622

${ }^{84}$ Dellinger RP, Levy MM, Carlet JM, et al. Surviving Sepsis Campaign: International guidelines for management of severe sepsis and septic shock: 2008. Crit Care Med 2008; 36(1):296-327. PMID: 18158437.

${ }_{55}$ Perrin BM, Gardner MJ, Suhaimi A, Murphy D. Charcot osteoarthropathy of the foot. Aust Fam Physician 2010; 39(3):117-119. PMID: 20369111.

86 Ulbrecht JS, Wukich DK. The Charcot foot: Medical and surgical therapy. Curr Diab Rep 2008; 8(6):444-45l. PMID: 18990300.

87 Frykberg RG, Mendeszoon E. Management of the diabetic Charcot foot. Diabetes Metab Res Rev 2000; 16(Suppl 1):S59-65. PMID: 11054891.

88 International Diabetes Federation. IDF Diabetes Atlas. Seventh Edition. Brussels: International Diabetes Federation, 2015. ISBN: 978-2-93022981-2.

${ }^{89}$ Kerr M, Rayman G, Jeffcoate WJ. Cost of diabetic foot disease to the National Health Service in England. Diabet Med 2014; 31(12):1498-1504. PMID: 24984759.

90 American Diabetes Association. Standards of Medical Care in Diabetes 2016: Summary of revisions. Diabetes Care 2016; 39 (Suppl 1):S4-5.

Keywords: Charcot, neuroarthropathy, diabetic foot, diabetic neuropathy 